\title{
Role of linkage structures in supply chain for managing greenhouse gas emissions
}

\author{
Ryoko Morioka ${ }^{1 *}$, Keisuke Nansai ${ }^{1,2}$ and Koji Tsuda ${ }^{3}$
}

\author{
*Correspondence: \\ morioka.ryoko@nies.go.jp \\ ${ }^{1}$ Center for Material Cycles \\ and Waste Management \\ Research, National Institute \\ for Environmental Studies, \\ 16-2 Onogawa, Tsukuba, \\ Ibaraki 305-8506, Japan \\ Full list of author information \\ is available at the end of the \\ article
}

\begin{abstract}
This study describes a structural decomposition analysis (SDA) of Japanese greenhouse gas (GHG) emissions from 1990 to 2005, focusing on four linkage structures in the Leontief inverse representing supply chains in Japan. The developed RAS-invariant decomposition was applied to Japanese linked input-output tables for the three 5 -year periods studied. It examined the effect of the Leontief inverse on emissions changes into the specific effects of forward linkage, backward linkage, the average of forward/ backward linkage and kernel structure. Our SDA method solves the problem of parameter independence completely. The accuracy of those effects has been improved mathematically compared with conventional methods. For example, it was detected that backward linkage contributes to an increase in GHG emissions, while conventional methods erroneously determine a decrease. The results of the SDA confirmed that forward linkage and kernel structure contributed to a rise in GHG emissions, and that backward linkage consistently increased emissions in the three periods. Some sectors have robust linkage in the supply chain with consistently increasing emissions, which should be preferentially improved to mitigate their indirect GHG emissions in Japan.
\end{abstract}

Keywords: Structural decomposition analysis, Input-output analysis, RAS, Information geometry

\section{Background}

The Paris Agreement adopted during the 21st Session of the Conference of the Parties (COP21) entered into force on November 4, 2016. It aims to reinforce global efforts to attain "the 1.5 or $2{ }^{\circ} \mathrm{C}$ target" deemed to limit global temperature rise this century to 1.5 to $2{ }^{\circ} \mathrm{C}$ above pre-industrial levels. Ratifying nations are required to make maximum efforts to reduce their greenhouse gas (GHG) emissions via their Nationally Determined Contributions (NDCs). The pathway to the 1.5 or $2{ }^{\circ} \mathrm{C}$ target is by no means simple and will inevitably involve major changes in current systems of production and consumption. Against this background, in-depth elucidation of the economic factors driving emission rise in each nation would help identify key suppliers and demanders where system decarbonization would have most effect. Structural decomposition analysis (SDA) in an input-output analysis (IOA) (Dietzenbacher and Los 1998; Dietzenbacher et al. 2000; Lianling and Cuihong 2017) is a useful tool for such an investigation. For 
example, environmental application of SDA allows both increases and decreases in GHG emissions to be quantitatively decomposed into the contributions of specific economic factors.

Numerous earlier environmental SDA studies (Nansai et al. 2007; Minx et al. 2011; Yamakawa and Peters 2011; Zhang et al. 2017) have demonstrated the major contributions of final demand and sectoral emission intensity (direct emission per unit production) to increase and decrease in national GHG emissions. National supply chain structure has, in other words, had less influence on emissions than either of these two factors. To achieve the dramatic emissions reduction implied by the 1.5 or $2{ }^{\circ} \mathrm{C}$ target via NDCs, however, it will be more productive to explore ways to further decarbonize the supply chain structure itself.

In an IOA, supply chain structure is elucidated by decomposing the Leontief inverse in various ways to describe the direct and indirect relationships between production sectors. For example, Miller and Blair (2009) focused on the changes in input coefficients and performed an additive decomposition of the Leontief inverse. Afrasiabi and Casler (1991) decomposed the change in the Leontief inverse into two terms representing technological and product-mix change. Sonis and Hewings (1998), on the other hand, applied Sherman and Morrison $(1949,1950)$ 's inverse matrix perturbation theory to perform time-incremental decomposition of the Leontief inverse in time series. Okuyama et al. (2006) provided an example of Sonis and Hewings' (1998) methodology, applying the time-incremental approach to the Leontief inverse and calculating the accumulated temporal impacts of demand increase for the sectors studied.

The two indices: backward and forward linkage, are often used to screen key sectors based on the Leontief inverse (Rasmussen 1956; Hirschman 1958; Lenzen 2003; Humavindu and Stage 2013; Alatriste-Contreras 2015; Haque and Jahan 2016; Nagashima et al. 2017). Backward linkage represents the power of dispersion of a sector, i.e., the degree to which production is induced in the sector's upstream supply chains per unit demand of the sector. It is quantified by dividing the column sums of the Leontief inverse by their average. Forward linkage indicates the sensitivity of dispersion of a sector, i.e., the degree to which unit production in the sector induces production in all the sectors in the downstream supply chain. It is measured by dividing the row sums of the Leontief inverse by their average. Sectors with backward and forward linkages greater than unity are recognized as key sectors. These two linkages can also be derived from the Ghosh model inverse matrices (Beyers 1976; Jones 1976; Dietzenbacher 1997).

Key sector analysis is grounded in the theoretical formulation by Sherman and Morrison $(1949,1950)$ of the relationship between changes in elements of the inverse matrix and elements of the input coefficient matrix. Woodbury (1950) extended the theory to encompass changes in multiple elements in the matrices. Bullard and Sebald (1977) applied the theory to update the inverse matrix in SAM (social accounting matrix) analysis and developed an algorithm yielding the correspondence among the elements. Using this method, Hewings and Romanos (1981) and Hewings et al. (1989) investigated the impact of changes in each element of the inverse matrix and the input coefficient matrix. They also applied the approach to SAM and explored the update relationship in each element of regional demand. Sonis et al. (2000) further elaborated the theory for row-/column-wise impact analysis. They also decomposed a term derived from the 
Leontief inverse into its diagonal, symmetric, and asymmetric elements. Chang and Lahr (2017) used key sector analysis to explore policy directions based on their SDA results on $\mathrm{CO}_{2}$ emissions.

However, while decomposition of the Leontief inverse and SDA are both fairly powerful tools for understanding the impact of changes in supply chain structure on the emissions of a national economy, to the best of our knowledge, except for a paper by Wood (2009) on Australian GHG emissions, no study has combined these tools for the specific purpose of environmental analysis. The cited paper decomposes the Leontief inverse into three factors: backward and forward linkages and an industrial structure matrix. However, a methodological problem is encountered in deriving the industrial structure matrix in terms of its invariance to the two linkages, as described in the following section in detail. The present study builds on the pioneering paper of Wood (2009) and addresses Japanese GHG emissions using a novel decomposition formulation of the Leontief inverse which theoretically overcomes the problem. Specifically, we analyze changes in Japanese domestic GHG emissions from 1990 to 2005 and characterize the effects of changes in backward and forward linkages on these emissions. The paper concludes by discussing the policy implications of our study for decarbonizing low-carbon supply chains.

\section{Methods and data}

\subsection{Structural decomposition analysis using the RAS method}

The RAS method can be used for decomposition and mechanical updating of a matrix, whereby " $\mathrm{R}$ " stands for the diagonal matrix of elements modifying rows, " $\mathrm{A}$ " is the matrix to be updated and " $\mathrm{S}$ " is the diagonal matrix of column modifiers, hence "RAS". There are two main forms of SDA: additive decomposition (Dietzenbacher and Los 1998) and multiplicative decomposition (Dietzenbacher et al. 2000), and both can be combined with the RAS method to decompose an input coefficient matrix or the Leontief inverse. For example, Dietzenbacher and Hoekstra (2002) analyzed the effects of R and S on the change in input coefficients by multiplicative SDA using the RAS method. Wood (2009) additively decomposed the Leontief inverse itself into three determinants: backward and forward linkage vectors and an industrial structure matrix, which was obtained by dividing the Leontief inverse into two matrices, as in the RAS method. Here, the first matrix has the forward linkage vector as its diagonal elements and zero for the others, while the second matrix has the backward linkage vector as its diagonal elements and zero for the others.

As long as it is based on this definition, however, the industrial structure matrix depends on the backward and forward linkage vectors. In other words, invariance of the matrix to the two vectors is not ensured, which means the industrial structure matrix is altered by the arbitrary vectors of the row and column sums given to the RAS method. This causes a problem in environmental SDA, where the impact of changes in the industrial structure matrix on GHG emissions is of necessity included by way of changes in backward and forward linkages. Indeed, the same problem is also faced by the structural indices described in de Mesnard (2004), Dietzenbacher and Hoekstra (2002), van der Linden and Dietzenbacher (2000), Lahr and de Mesnard (2004). 
In order to overcome the above problem of invariance in the industrial structure, this study developed a methodology to identify a novel structure matrix (here named "kernel structure matrix") that is completely independent of changes in the row and column sums in the RAS method, and applied the method to decomposition of the Leontief inverse into four determinants: vector $\boldsymbol{F L}$ (forward linkage), vector $\boldsymbol{B} \boldsymbol{L}$ (backward linkage), scalar $A V$ (average of forward/backward linkage) and matrix $\boldsymbol{K S}$ (kernel structure matrix of linkage). The derivation and advantage of the kernel structure matrix are described in Sect. 3. In concreto, we used the Japanese linked-IO tables published by Japan's Ministry of Internal Affairs and Communications, with reference prices adjusted to the year 2005, and combined these with sectoral GHG emissions data (Nansai et al. 2003). The IO tables consist of $397 \times 397$ sectors for the years 1990, 1995, 2000 and 2005. Latest annual IO table is the year of 2011 and latest linked-IO table covers 2000-20052011; however, no GHG emission data are compiled for 2011 yet. Additionally, in 2011, there was a big earthquake in Japan, and power generation and many industries had unexpected impact about their productions and demands. The linked-IO table for 19902005 seems outdated, but we believe the IO data until 2005 that we used represents the ordinal feature of Japanese industrial formation. GHG emissions comprise carbon dioxide $\left(\mathrm{CO}_{2}\right.$ : both fuel-derived and non-fuel-derived), methane $\left(\mathrm{CH}_{4}\right)$, nitrous oxide $\left(\mathrm{N}_{2} \mathrm{O}\right)$, perfluorocarbons $\left(\mathrm{PFC}_{s}\right)$, hydrofluorocarbons $\left(\mathrm{HFC}_{s}\right)$ and sulfur hexafluoride $\left(\mathrm{SF}_{6}\right)$. The global warming potentials for a 100-year time horizon defined in the Intergovernmental Panel on Climate Change's Fourth Assessment Report were applied to convert emissions of GHGs other than $\mathrm{CO}_{2}$ into $\mathrm{CO}_{2}$-equivalents.

An environmental input-output model formulates the domestic GHG emissions induced by final demand by Eq. (1), in which Q denotes the induced GHG emissions, vector $\boldsymbol{d}$ the direct GHG emission intensity, A the input coefficients matrix for domestic products and $y$ the final demand vector for domestic products. L represents the Leontief inverse.

$$
Q=d(I-A)^{-1} y=d L y .
$$

Here, $\boldsymbol{F} \boldsymbol{L}, \boldsymbol{B} \boldsymbol{L}, A V$ are defined as follows:

$$
\begin{aligned}
& \boldsymbol{F}_{i}=\frac{\sum_{j=1}^{n} L_{i j}}{\frac{1}{n} \sum_{i=1}^{n} \sum_{j=1}^{n} L_{i j}} . \\
& \boldsymbol{B} \boldsymbol{L}_{j}=\frac{\sum_{i=1}^{n} L_{i j}}{\frac{1}{n} \sum_{i=1}^{n} \sum_{j=1}^{n} L_{i j}} . \\
& A V=\frac{1}{n} \sum_{i=1}^{n} \sum_{j=1}^{n} L_{i j} .
\end{aligned}
$$

According to the decomposition based on information geometry, $\boldsymbol{L}$ is orthogonally decomposed as follows:

$$
\boldsymbol{L}=\phi(\boldsymbol{F L}, \boldsymbol{B L}, A V, \boldsymbol{K S}) .
$$


This decomposition $\phi$ cannot be explicitly expressed, but uses numerical calculations including the RAS method. $\phi$ is the transformation that reconstructs L from decomposed values using the RAS method.

Thus, $\phi$ is defined as follows:

$$
\phi(\boldsymbol{F} \boldsymbol{L}, \boldsymbol{B} \boldsymbol{L}, A V, \boldsymbol{K S})=R A S(\exp (\boldsymbol{K S}), \mathrm{AV} \times \boldsymbol{F} \boldsymbol{L}, \mathrm{AV} \times \boldsymbol{B} \boldsymbol{L})
$$

where RAS refers to the numerical operation using the RAS method and exp means element-wise exponential. The details of the reconstruction is explained in Sect. 2.2.1.

From Eqs. (1) and (5), $Q$ is represented by:

$$
\begin{aligned}
Q & =d L y \\
& =d \phi(F L, B L, A V, K S) y .
\end{aligned}
$$

There are two forms of SDA: an additive and a multiplicative formulation (Dietzenbacher and Los 1998; Dietzenbacher et al. 2000). Though our decomposition can apply to both, this time we use the multiplicative formulation. In the following SDA formulation, $\Delta$ means change of GHG emissions due to the change in target parameter, in short, the effect of the parameter on GHG emissions. Applying the full-multiplicative SDA scheme (Dietzenbacher et al. 2000) to obtain the change in $Q(\Delta Q), \Delta Q$ can be expressed as the product of the changes in the six determinants, as in the following Eq. (8):

$$
\begin{aligned}
\Delta Q & =\Delta \boldsymbol{d} \times \Delta \boldsymbol{L} \times \Delta \boldsymbol{y} \\
& =\Delta \boldsymbol{d} \times \Delta \boldsymbol{F} \boldsymbol{L} \times \Delta \boldsymbol{B} \boldsymbol{L} \times \Delta A V \times \Delta \boldsymbol{K} \boldsymbol{S} \times \Delta \boldsymbol{y} .
\end{aligned}
$$

Here, $\Delta \boldsymbol{d}$ indicates the effect of a change in direct GHG emission intensity, $\Delta \boldsymbol{F} \boldsymbol{L}$ the effect of $\boldsymbol{F} \boldsymbol{L}, \Delta \boldsymbol{B} \boldsymbol{L}$ the effect of $\boldsymbol{B} \boldsymbol{L}, \Delta A V$ the effect of $A V, \Delta \boldsymbol{K S}$ the effect of $\boldsymbol{K S}$ and $\Delta \boldsymbol{y}$ the effect of a change in final demand. $\Delta L=\Delta \boldsymbol{F} \boldsymbol{L} \times \Delta \boldsymbol{B} \boldsymbol{L} \times \Delta A V \times \Delta \boldsymbol{K S}$ indicates the effect of a change in the whole of the Leontief inverse.

In addition, we examined the effects of individual changes in the backward and forward linkages of each sector, $\Delta \boldsymbol{F} \boldsymbol{L}_{i}$ and $\Delta \boldsymbol{B} \boldsymbol{L}_{j}$, by further decomposing $\Delta \boldsymbol{F} \boldsymbol{L}$ and $\Delta \boldsymbol{B} \boldsymbol{L}$ as Eqs. (9) and (10). Here, $\Delta \boldsymbol{F} \boldsymbol{L}_{\bar{i}}$ and $\Delta \boldsymbol{B} \boldsymbol{L}_{\bar{j}}$ denote the effects of all other sectors except the target sector $i$ or $j$.

$$
\begin{aligned}
& \Delta \boldsymbol{F} \boldsymbol{L}=\Delta \boldsymbol{F} \boldsymbol{L}_{\bar{i}} \times \Delta \boldsymbol{F} \boldsymbol{L}_{i} . \\
& \Delta \boldsymbol{B} \boldsymbol{L}=\Delta \boldsymbol{B} \boldsymbol{L}_{\bar{j}} \times \Delta \boldsymbol{B} \boldsymbol{L}_{j} .
\end{aligned}
$$

\subsection{Kernel structure matrix based on information geometry}

In this section, derivation of the kernel structure matrix is simply explained using decomposition of an IO table as an example. To decompose the space of an IO table into the scale of the row/column sums (hereafter referred to as the marginal sums) and the space of an industrial structure, we introduce dual and mixed coordinates and perform orthogonal decomposition. First, the columns of the endogenous sectors of an IO table are accumulated to transform them into vectors (hereafter referred to as vec) $\boldsymbol{a}$. Let the number of endogenous industrial sectors in the columns and rows be $n$. See Supporting Information for the sample case of $n=3$. The number of elements in $x$ is $N=n^{2}$. Let a basis $\left\{\boldsymbol{b}_{i}\right\}_{i=1}^{N}$ represent sets of linearly independent vectors and let $C_{i}$ be an $n \times n$ matrix in which the elements of the $i$ th row are 1 and all the other elements are zero and is defined as follows: 


$$
\begin{aligned}
& \boldsymbol{b}_{i}=\mathbf{1}, \quad \text { if } i=1 \\
& \boldsymbol{b}_{i}=\operatorname{vec}\left(C_{i-1}\right), \quad \text { if } i=2, \ldots, n \\
& \boldsymbol{b}_{i}=\operatorname{vec}\left(C_{i-n}^{\prime}\right), \quad \text { if } i=n+1, \ldots, 2 n-1 .
\end{aligned}
$$

Here, the prime means transpose.

For the first $2 n-1$ vectors, $\boldsymbol{a}^{\prime} \boldsymbol{b}_{i}$ corresponds to the marginal sum. In information geometry, $a$ is expressed by two mutually dual coordinate systems: an $m$-coordinate system and an $e$-coordinate system (Amari and Nagaoka 2000). The $m$-coordinate system is defined as:

$$
\eta=\boldsymbol{B}^{\prime} \boldsymbol{a} .
$$

where $\boldsymbol{B}$ is a matrix having columns $\left\{\boldsymbol{b}_{i}\right\}_{i=1}^{N}$. The first $2 n-1$ elements of $\boldsymbol{\eta}$ are represented as $\eta^{A}$, which corresponds to the marginal sum, and the remaining elements are defined as $\eta^{B}$. On the other hand, the $e$-coordinate system $\boldsymbol{\theta}$ is defined as:

$$
\boldsymbol{\theta}=\boldsymbol{B}^{-1} \log \boldsymbol{a} .
$$

Like $\eta$, the first $2 n-1$ elements of $\boldsymbol{\theta}$ and the remaining elements are separated and defined as $\boldsymbol{\theta}^{A}$ and $\boldsymbol{\theta}^{B}$. Furthermore, a mixed coordinate system $\boldsymbol{\xi}=\left(\boldsymbol{\eta}^{A}, \boldsymbol{\theta}^{B}\right)$ is introduced.

Next, the distance between different IO tables is considered. When vectors of two different IO tables exist, the Kullback-Leibler (KL) divergence is expressed as:

$$
D(\boldsymbol{p}, \boldsymbol{q})=\sum_{i=1}^{N} p_{i} \log p_{i}-p_{i} \log q_{i}-p_{i}+q_{i}
$$

In general, when mapping a point $x$ to a manifold $\mathcal{S}$, the following two types of projection exist, because KL divergence is asymmetric (Amari and Nagaoka 2000).

- e-projection:

$$
\boldsymbol{q}^{*}=\operatorname{argmin}_{\boldsymbol{q} \in \mathcal{S}} D(\boldsymbol{q}, \boldsymbol{x})
$$

- $m$-projection:

$$
\boldsymbol{q}^{*}=\operatorname{argmin}_{\boldsymbol{q} \in \mathcal{S}} D(\boldsymbol{x}, \boldsymbol{q})
$$

Vazquez et al. (2015) proved that the general RAS method is an $e$-projection which minimizes KL divergence (Censor and Zenios 1997).

Next, we express a known, statistically corrected IO table as $\boldsymbol{a}_{1}:\left(\boldsymbol{\eta}_{1}^{A}, \boldsymbol{\theta}_{1}^{B}\right)$, and consider operation $R$, which calculates a table that transformed its scale from $a_{1}$ to $a_{2}$ by the RAS method conditional on the marginal sum of another IO table $\boldsymbol{a}_{2}:\left(\boldsymbol{\eta}_{2}^{A}, \boldsymbol{\theta}_{2}^{B}\right)$. Then,

$$
\boldsymbol{a}_{3}=R\left(\boldsymbol{a}_{1}, \boldsymbol{\eta}_{2}^{A}\right)
$$


Here, because the RAS method is an $e$-projection, the generalized Pythagorean theorem described below holds, and orthogonal decomposition can be considered (Amari and Nagaoka 2000).

$$
D\left(\boldsymbol{a}_{2}, \boldsymbol{a}_{1}\right)=D\left(\boldsymbol{a}_{2}, \boldsymbol{a}_{3}\right)+D\left(\boldsymbol{a}_{3}, \boldsymbol{a}_{1}\right) .
$$

The terms on the right-hand side correspond to the marginal sum and structure. Regarding the basis of the orthogonal decomposition, the RAS method changes only the marginal sum and the amount representing the structure therefore corresponds to the RAS invariants. Consider the RAS invariants in the $\boldsymbol{\theta}$-coordinate system and decompose an IO table vector $\boldsymbol{a}$ in logarithmic space as follows:

$$
\log \boldsymbol{a}=\boldsymbol{B}_{1} \boldsymbol{\theta}^{A}+\boldsymbol{B}_{2} \boldsymbol{\theta}^{B},
$$

In this equation, the second term on the right-hand side corresponds to the RAS invariants. Here, $\boldsymbol{B}_{1}$ consists of column vectors with basis $\boldsymbol{b}_{1}, \ldots, \boldsymbol{b}_{2 n-1}$ and $\boldsymbol{B}_{2}$ is the remaining basis. To allow this decomposition to divide the RAS invariants and orthogonal space, the elements of $\boldsymbol{B}_{1}$ and $\boldsymbol{B}_{2}$ must be mutually orthogonal. We therefore define

$$
\boldsymbol{b}_{k}^{\prime} \boldsymbol{b}_{l}=0, k=1, \ldots, 2 n-1, l=2 n, \ldots, N .
$$

Let $V_{r}$ be the space generated by changing only the marginal sum by the RAS method.

$$
V_{r}=\left\{\boldsymbol{v} \mid \boldsymbol{v}=\log R(\boldsymbol{a}, \boldsymbol{s})-\log \boldsymbol{a}, \boldsymbol{a}, \boldsymbol{s} \in \mathfrak{R}_{+}\right\} .
$$

Here, $R$ is the transformation obtained by the RAS method, which equals the space $V$ spanned by basis $\boldsymbol{b}_{1}, \ldots, \boldsymbol{b}_{2 n-1}$.

$$
V=\left\{\boldsymbol{v} \mid \boldsymbol{v}=\beta_{1} \boldsymbol{b}_{1}+\cdots+\beta_{2 n-1} \boldsymbol{b}_{2 n-1}, \beta_{i} \in \mathfrak{R}, i=1, \ldots, 2 n-1\right\}
$$

Let $U$ be the orthogonal complement of $V$, such that

$$
U=\left\{\boldsymbol{u} \mid \boldsymbol{u}^{\prime} \boldsymbol{v}=0, \boldsymbol{v} \in V\right\}
$$

holds and equals the space spanned by $B_{2}$. Therefore, consider the projective space $V$ from the IO table vector $a$ to $U$. Then, consider the projective space V from the IO table vector a to $\mathrm{U}$, and rewrite the elements of the RAS invariant $\boldsymbol{\theta}^{B}$ as elements of a matrix in which the columns are reaccumulated. Thus,

$$
\begin{aligned}
\mathcal{K}_{i j}:= & \log a_{i j}-\frac{1}{n} \sum_{k=1}^{n} \log a_{i k}-\frac{1}{n} \sum_{k=1}^{n} \log a_{k j} \\
& +\frac{1}{n^{2}} \sum_{k=1}^{n} \sum_{l=1}^{n} \log a_{k l}
\end{aligned}
$$

holds. This matrix, the elements of which include matrix $\mathcal{K}$ as an RAS invariant inherent to the original IO table $\boldsymbol{a}$, is reaccumulated and can be referred to as an "industrial structure" to borrow the expression of Wood (2009). However, as this matrix is purely RASinvariant, we call it a "kernel structure matrix", which is a matrix in which the amounts correspond to RAS invariants in both the row and the column directions and are averaged to zero at the center. 


\subsubsection{Reconstruction of a new IO table based on the kernel structure matrix}

Although the orthogonal decomposition of the IO tables has so far been considered using a marginal sum and kernel structure matrix, IO tables can also be reconstructed by combining various marginal sums and kernel structure matrices. Reconstruction goal is make a matrix $\boldsymbol{a}_{0}$ as $\left(\boldsymbol{\eta}_{0}^{A}, \boldsymbol{\theta}_{0}^{B}\right)$ denoted by the mixed coordinates, whose kernel structure matrix is $\mathcal{K}_{\text {any }}$ and whose marginal sum is $\boldsymbol{\eta}_{\text {any }}^{A}$ corresponding to $A V \times \boldsymbol{F L}$ and $A V \times \boldsymbol{B L}$ in SDA formulation. Here, $e$-coordinates of $\exp \left(\mathcal{K}_{\text {any }}\right)$ are $\boldsymbol{\theta}^{A}=0, \boldsymbol{\theta}^{B}=\boldsymbol{\theta}_{0}^{B}$. Also, the RAS method can change the first half of the mixed coordinates $\eta^{A}$ to $\eta_{0}^{A}$ while keeping $\boldsymbol{\theta}^{B}$ unchanged. Therefore, $\boldsymbol{a}_{0}$ is calculated using $\exp \left(\mathcal{K}_{\text {any }}\right)$ and the RAS method as follows:

$$
\boldsymbol{a}_{\text {new }}=\phi\left(\exp \left(\mathcal{K}_{\text {any }}\right), \eta_{\text {any }}^{A}\right)
$$

Here, $\phi$ is a numerical operation performed using the RAS method, which repeats the following two steps until convergence. Regarding $T=\exp (\mathcal{K})$ and $\eta$, let $r$ refer to the parts corresponding to the row sums, and let $s$ denote those corresponding to the column sums.

- Multiply the rows of $T$ by the coefficients such that the row sums are identical with $\boldsymbol{r}$.

- Multiply the columns of $T$ by the coefficients such that the column sums are identical with $s$.

In Sect. 3, it is mentioned that a reconstructed $\boldsymbol{L}_{\text {new }}$ and its $\boldsymbol{K S}$ are similar. According to Eq. (27), $\boldsymbol{L}_{\text {new }}$ is reconstructed using RAS method with $\boldsymbol{K S}$. Also, Eq. (16) explains that RAS result is closest solution from the original matrix. Therefore, $\boldsymbol{L}_{\text {new }}$ and other any derived matrices are similar with the original $K S$ from the viewpoint of KL divergence. In this study, we explored the "structure" in $\boldsymbol{L}$ from the viewpoint of RAS-invariant, and one of the solutions was the kernel structure matrix. Kernel structure matrix is one of the decomposed elements of $\boldsymbol{L}$, and it has a characteristic: All row sums and column sums are zero.

\section{Characteristics of kernel structure matrix}

\subsection{Economic and environmental interpretation of kernel structure}

The decomposition/reconstruction method based on the RAS-invariant approach allows a Leontief inverse to be manipulated via each of the linkage parameters while maintaining independence among all parameters. The independence of the kernel structure matrix that is invariant with respect to the other parameters increases the accuracy of the SDA and is the key improvement over the calculation by Wood (2009). $\boldsymbol{F L}$ and $\boldsymbol{B} \boldsymbol{L}$ can be updated independently in the reconstruction of $\boldsymbol{L}$ by simple manipulation, because $\boldsymbol{K S}$ is independent of $\boldsymbol{F L}$ and $\boldsymbol{B} \boldsymbol{L}$. This numerical example is provided in the Additional file 1. Additional file 1: Figure A1 shows an example of reconstruction of the Leontief inverse using the four linkage structures used in our SDA process.

Economic interpretation of $\boldsymbol{K S}$ of $\boldsymbol{L}$ is inherent direct and indirect relations among industries, in other words, intensity of an industrial network in supply chain. Because $\boldsymbol{K S}$ is completely independent of $\boldsymbol{F} \boldsymbol{L}$ and $\boldsymbol{B} \boldsymbol{L}$, large $(i, j)$ elements in $\boldsymbol{K S}$ tend to have large 
elements in the original IO table, too, regardless of any $\boldsymbol{F} \boldsymbol{L}$ and $\boldsymbol{B} \boldsymbol{L}$ values. Similarly, small $(i, j)$ elements in $\boldsymbol{K S}$ tend to have small elements in the original IO table, too.

If some $(i, j)$ element in a kernel structure matrix is relatively large, the $(i, j)$ element in the conversion result $\boldsymbol{L}$ tends to be larger than the other elements. This is because that the kernel structure matrix and the result of RAS conversion based on the matrix are close in the sense of KL divergence, or a pseudometric. Therefore, any $(i, j)$ large element in the kernel structure matrix tends to have larger ripple effect of $\boldsymbol{L}$ than other elements, despite values of $\boldsymbol{F} \boldsymbol{L}$ and $\boldsymbol{B} \boldsymbol{L}$.

For this property of the kernel structure matrix, exploring of $\boldsymbol{K S}$ values allows us to find potentially intensive economic transactions. This is applicable to a general environmental IO model of $\boldsymbol{d} \boldsymbol{L}$, because $\boldsymbol{K S}$ of $\boldsymbol{L}$ and the $\boldsymbol{K S}$ of $\operatorname{diag}(\boldsymbol{d}) \times \boldsymbol{L}$ are exactly the same. Large $(i, j)$ elements in the $\boldsymbol{K S}$ of $\operatorname{diag}(\boldsymbol{d}) \times \boldsymbol{L}$ indicate industrial relations with potentially large environmental burden, regardless of values of $\boldsymbol{d}$, the sectoral direct environmental burden per unit output.

\subsection{Advantage over the conventional approach}

As with our SDA application, there are three possible SDA formulations for analyzing FL and BL effects on GHG emissions.

First, there is a straightforward decomposition of $\boldsymbol{L}$ ('method 1'), without our decomposition method using $K S$. Here, the effect of $\boldsymbol{F} \boldsymbol{L}$ or $\boldsymbol{B} \boldsymbol{L}$ is calculated separately.

In the case of the decomposition focusing on $\boldsymbol{B} \boldsymbol{L}, \hat{\boldsymbol{L}}$ is defined as

$$
\boldsymbol{L}^{m 1}=\boldsymbol{L}_{i j} / \sum_{i} \boldsymbol{L}_{i j}=\boldsymbol{L}_{i j} /(\boldsymbol{B} \boldsymbol{L} \times A V)_{j}
$$

Here, $\hat{\boldsymbol{B}} \boldsymbol{L}$ is defined as a diagonal matrix of $\boldsymbol{B} \boldsymbol{L} \times A V$. Using $\hat{\boldsymbol{L}}$ and $\hat{\boldsymbol{B} \boldsymbol{L}}$, consider the following SDA for GHG emissions $Q$,

$$
\Delta Q=\Delta \boldsymbol{d} \times \Delta \boldsymbol{L}^{m 1} \times \Delta \hat{\boldsymbol{B} L} \times \Delta \boldsymbol{y}
$$

$\Delta \hat{\boldsymbol{B L}}^{m 1}$ from year 1 to 2 is

$$
\Delta \hat{\boldsymbol{B L}}^{m 1}=\left(\frac{\boldsymbol{d}_{1} \times \boldsymbol{L}_{1}^{m 1} \times \hat{\boldsymbol{B}}_{2} \times \boldsymbol{y}_{1}}{\boldsymbol{d}_{1} \times \boldsymbol{L}_{1}^{m 1} \times \hat{\boldsymbol{L}}_{1} \times \boldsymbol{y}_{1}} \times \frac{\boldsymbol{d}_{1} \times \boldsymbol{L}_{2}^{m 1} \times \boldsymbol{B} \hat{\boldsymbol{L}}_{2} \times \boldsymbol{y}_{1}}{\boldsymbol{d}_{1} \times \boldsymbol{L}_{2}^{m 1} \times \boldsymbol{B} \hat{\boldsymbol{L}}_{1} \times \boldsymbol{y}_{1}} \times \cdots\right)^{1 / 4 !}
$$

Here, for convenience of explanation, the parameters of $\boldsymbol{L}, \boldsymbol{B} \boldsymbol{L}$ are extracted from the SDA calculation, under the assumption that the other parameters remain unchanged. For example, $\frac{\boldsymbol{L}_{2}^{m 1}}{\boldsymbol{L}_{1}^{m 1}} \times \frac{\hat{\boldsymbol{B}} \boldsymbol{L}_{1}}{\hat{\boldsymbol{B}}_{1}}$ in $\Delta \boldsymbol{L}^{m 1}$ calculation shows the change of $\boldsymbol{L}^{m 1}$. However, when $\boldsymbol{L}^{m 1}$ changes, $\boldsymbol{B} \boldsymbol{L}$ also changes except the special case like Case 1 in Figure A1, which is an example of $\boldsymbol{L}$ 's change keeping $\boldsymbol{B} \boldsymbol{L}$ exactly ( see the Additional file 1). Analogous to above example, a part of Eq. (30), $\frac{\boldsymbol{L}_{1}^{m 1}}{\boldsymbol{L}_{1}^{m 1}} \times \frac{\hat{\boldsymbol{B}} \boldsymbol{L}_{2}}{\hat{\boldsymbol{B} \boldsymbol{L}_{1}}}$, means $\boldsymbol{B} \boldsymbol{L}$ change. Nevertheless, the change in $\boldsymbol{B} \boldsymbol{L}$ follows the change in $\boldsymbol{L}^{m 1}$ based on Eq. (28). This formulation does not separate the effects of $\boldsymbol{L}^{m 1}$ and $\boldsymbol{B} \boldsymbol{L}$, since $\boldsymbol{L}^{m 1}$ and $\boldsymbol{B} \boldsymbol{L}$ are mutually dependent. 
In the case of the decomposition focusing on $\boldsymbol{F L}$ ('method 2'), $\boldsymbol{L}^{m 2}$ is defined as

$$
\boldsymbol{L}^{m 2}=\boldsymbol{L}_{i j} / \sum_{j} \boldsymbol{L}_{i j}=\boldsymbol{L}_{i j} /(\boldsymbol{F} \boldsymbol{L} \times A V)_{i}
$$

$\breve{\boldsymbol{F}}$ is defined as a diagonal matrix of $\boldsymbol{F L} \times A V \cdot \Delta \breve{\boldsymbol{F}}{ }^{m 2}$ from year 1 to 2 is

$$
\Delta \breve{\boldsymbol{F L}}^{m 2}=\left(\frac{\boldsymbol{d}_{1} \times \breve{\boldsymbol{F}}_{2} \times \boldsymbol{L}_{1}^{m 2} \times \boldsymbol{y}_{1}}{\boldsymbol{d}_{1} \times \breve{\boldsymbol{F}}_{1} \boldsymbol{L}_{1}^{m 2} \times \boldsymbol{y}_{1}} \times \frac{\boldsymbol{d}_{1} \times \breve{\boldsymbol{F}}_{2} \times \boldsymbol{L}_{2}{ }^{m 2} \times \boldsymbol{y}_{1}}{\boldsymbol{d}_{1} \times \breve{\boldsymbol{L}}_{1} \boldsymbol{L}_{2}{ }^{m 2} \times \boldsymbol{y}_{1}} \times \cdots\right)^{1 / 4 !}
$$

For the same reason as with the $\hat{\boldsymbol{B} L}$ case, this formulation does not separate the effects of $\boldsymbol{L}^{m 2}$ and $\breve{\boldsymbol{F}} \boldsymbol{L}$ either.

Using the above two formulations, consider the following SDA.

$$
\Delta Q=\Delta \boldsymbol{d} \times \Delta \breve{\boldsymbol{F}} \times \Delta \tilde{\boldsymbol{L}} \times \Delta \hat{\boldsymbol{B} L} \times \Delta \boldsymbol{y} .
$$

Using the above SDA results of Eqs. (30) and (32), $\Delta \tilde{\boldsymbol{L}}$ can immediately be obtained as a residual parameter. The numerical results of $\Delta \hat{\boldsymbol{B L}}^{m 1}$ and $\Delta \breve{\boldsymbol{F}}^{m 2}$ obtained using the above two SDAs are in fact not equal to the true $\Delta \boldsymbol{B} \boldsymbol{L}$ and $\Delta \boldsymbol{F L}$. The correct result of SDA (33) cannot therefore be obtained using the combined results of SDAs (30) and (32).

The third formulation is another combinatorial approach involving the above two linkage decompositions by Wood (2009), which we term 'method 3. This formulation calculates the effects of $\boldsymbol{F L}$ and $\boldsymbol{B L}$ simultaneously.

$$
\boldsymbol{L}=\breve{\boldsymbol{F}} \times \frac{\boldsymbol{L}}{\sum_{i} \boldsymbol{L}_{i j} \times \sum_{j} \boldsymbol{L}_{i j}} \times \hat{\boldsymbol{B L}}=\breve{\boldsymbol{F} L} \times \boldsymbol{L}^{m 3} \times \hat{\boldsymbol{B} \boldsymbol{L}}
$$

In this case $\boldsymbol{L}$ is decomposed into three linkages. This SDA does not isolate the effects of $\breve{\boldsymbol{F L}}$ and $\hat{\boldsymbol{B L}}$ or $\Delta \breve{\boldsymbol{F L}}^{m 3}$ and $\Delta \hat{\boldsymbol{B L}}^{m 3}$, because the three linkage parameters, $\breve{\boldsymbol{F L}}, \grave{\boldsymbol{L}}, \hat{\boldsymbol{B L}}$ are not independent.

The conclusion is therefore that parameter independence is important when the effects of linkage parameters are calculated using SDA.

\section{Results}

\subsection{The key linkages of Japanese supply chains}

\subsubsection{Change in AV}

We now apply the novel methodology elucidated above to Japanese supply chains. The value of $A V$ (average of forward/backward linkage) for the year 1990 is 2.0609 , which is the largest ripple effect among the 4 years considered. The value of $A V$ is 2.0079 in 1995 and 1.9831 in 2000 . The last $A V$ is 1.9463 , in 2005, which is the smallest ripple effect among the 4 years.

\subsubsection{Change in FL and BL}

Figure 1 plots $\boldsymbol{F L}$ (forward linkage) against $\boldsymbol{B L}$ (backward linkage) for each sector in each of the 4 years. The major key sectors for which both $\boldsymbol{F L}$ and $\boldsymbol{B} \boldsymbol{L}$ are greater than unity are immediately apparent.

Three sectors have a strong $\boldsymbol{F} \boldsymbol{L}$ throughout the entire period: "Plastic products" (sector 138), "Advertising" (366) and "Hot-rolled steel" (163). "Plastic products" has its 
maximum value in 1990 and a minimum in 2005. In addition, "Other electric components" (244) is a sector with a high $\boldsymbol{F L}$ in 1990 and 1995 (Fig. 1a, b). The $\boldsymbol{F} \boldsymbol{L}$ of "Structural repair" (280) is high in 1990 (Fig. 1a), while that of "Mechanical repair" (370) is high in 1995 (Fig. 1b). In the years 2000 and 2005 the same top $5 \boldsymbol{F L}$ sectors are observed: e the three sectors common to all 4 years, plus "Mechanical repair" (370) and "Structural repair" (280) (Fig. 1c, d).

$\boldsymbol{B} \boldsymbol{L}$ exhibits greater annual variation than $\boldsymbol{F} \boldsymbol{L}$. The common sector with a strong $\boldsymbol{F} \boldsymbol{L}$ in all 4 years is "Slaughter" (34), with a value that peaks in 1990 and declines in 1995 (Fig. 1a, b). The $\boldsymbol{B} \boldsymbol{L}$ of gIntegrated circuits h (240) is strong in 1990 and 1995, although its value in 1995 is the lowest for a $\boldsymbol{B} \boldsymbol{L}$ top sector in any years (Fig. 1b). The $\boldsymbol{B} \boldsymbol{L} \mathbf{s}$ of "Thermoplastic resins" (121) and "Cyclic intermediates" (113) are consistently strong in 1990, 1995 and 2000 (Fig. 1a-c). The sector "Office supplies" (396) has the highest $\boldsymbol{B L}$ in 1990 and 2000 (Fig. 1a, c). The $\boldsymbol{B} \boldsymbol{L}$ of "Aliphatic intermediates" (112) is also consistently strong from 1995 to 2005 (Fig. 1b, c and d). The $\boldsymbol{B} \boldsymbol{L}$ top 5 in 2005 additionally includes "Coated steel" (166), "Iron and steel shearing and slitting" (170) and "Auto parts" (250) (Fig. 1d).

\subsubsection{Change in KS}

Figure 2 shows the whole image of aggregated kernel structure matrices of each year. Since the size of $K S, 397^{2}$, is too large to visually grasp features, we made aggregated matrices of $\boldsymbol{K S}$, whose size is $21^{2}$, close resolution to above $\boldsymbol{F} \boldsymbol{L}$ and $\boldsymbol{B} \boldsymbol{L}$ analysis. It should

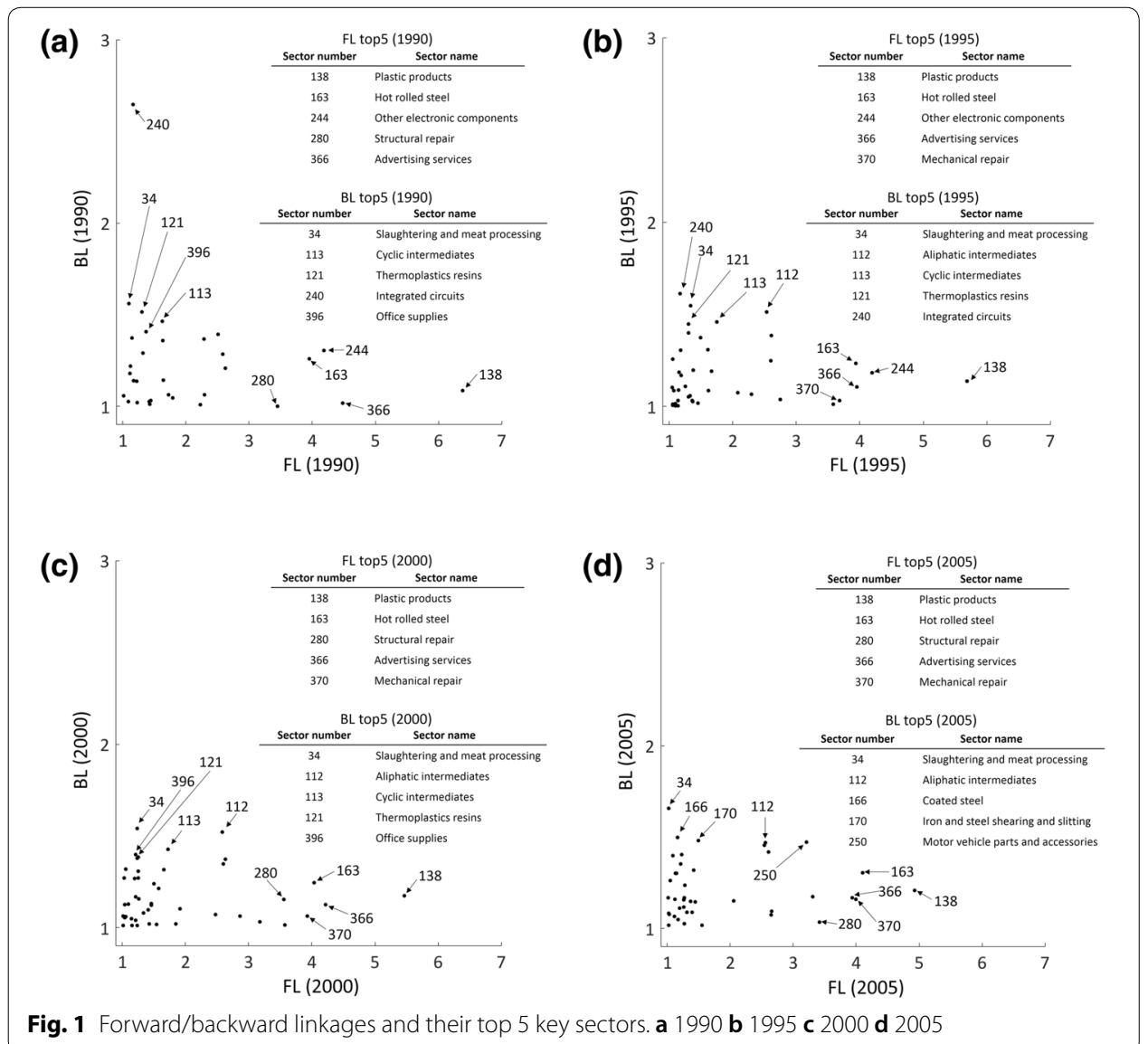


(a)

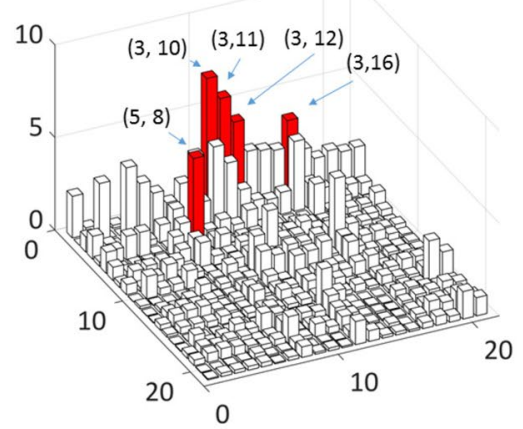

(c)

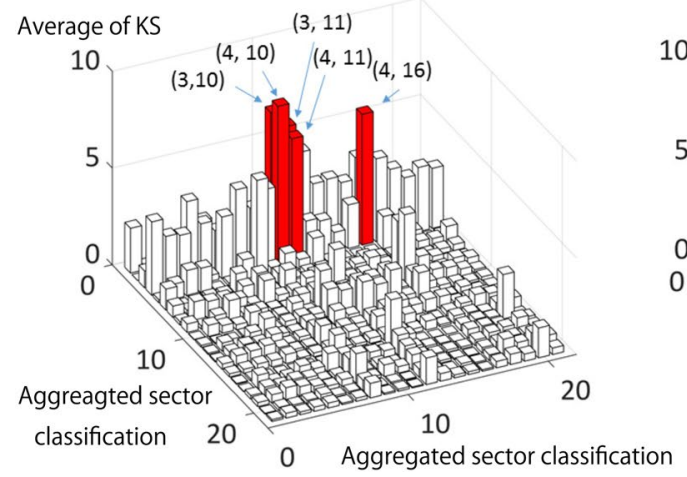

(b)

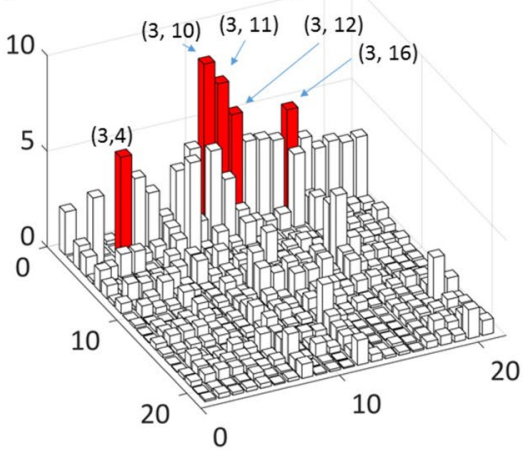

(d)

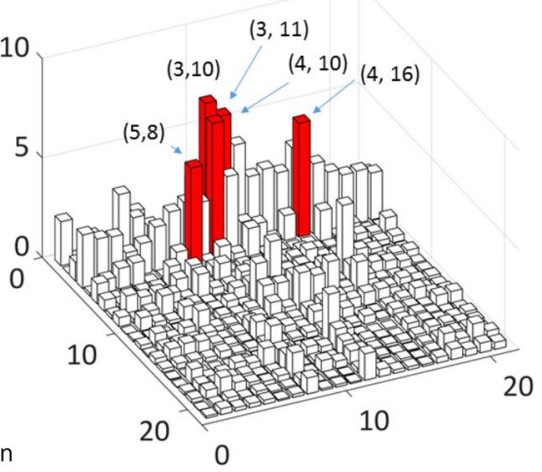

Fig. 2 Kernel structure matrices and their top 5 aggregated sectors in the years of a 1990, b 1995, c 2000, d 2005. The set number on the bars shows the number of aggregated sectors those are in the top 5 in each year. For plotting, values in the diagonal position and negative values are replaced with zero. 21 sector classifications aggregated from 379 sectors; 1 . agriculture, forestry and fisheries; 2 . metal mining; 3. ceramics and materials of earth and stones; 4. stone (non-ferrous stone); 5 . coal, crude petroleum, and natural gas; 6. food and drink, fibers, and paper and pulp; 7. chemistry; 8. petroleum and coal products; 9. other commodities ; 10. cement; 11. other ceramic, stone, and clay products; 12 . iron and steel; 13. machinery, equipment, and others; 14. transport vehicle; 15. other manufacturing; 16. construction; 17. electricity, gas, and water; 18. commerce, finance, and real estate; 19. transport; 20. information and communications; 21. services

be noted that this aggregation averages the features of the original $K S$ with $397^{2}$ elements. The aggregated kernel structure matrix is based on the following 21 sector classifications aggregated from 379 sectors; see legend of Fig. 2. For plotting, values in the diagonal position and negative values are replaced with zero in original kernel structure matrices, since we focused on the cross-sectoral, positive effects on GHG emission increase. The positive values in diagonal position of the aggregated matrices are caused by positive values in non-diagonal elements in the original kernel structure matrices.

Figure 2 shows stable characteristic of kernel structure matrix. There are numerical difference among 4 years, but major industries which have constant large intensities through the years are appeared. Top 5 aggregated sectors in each year are labeled on the bar with the numbers of input and output sector. The two aggregated flows are in top 5 in all years. The two flows are: from "Ceramics and materials of earth and stones" to "Cement" and from "Ceramics and materials of earth and stones" to "Other ceramic, stone, and clay products". The two flow from "Ceramics and materials of earth and 
stones" to "Iron and steel" and from "Ceramics and materials of earth and stones" to "Construction" are in the top 5 in the year of 1990 and 1995. The two flow from "Stone (non-ferrous stone)" to "Cement" and from "Stone (non-ferrous stone)" to "Construction" are in the ranking in the year of 2000 and 2005. The flow from "Coal, crude petroleum, and natural gas" to "Petroleum and coal products" is in the ranking in the year of 1990 and 2005. The other top 5 elements are the flow from "Ceramics and materials of earth and stones" to "Stone (non-ferrous stone)" in 1995 and from "Stone (nonferrous stone)" to "Other ceramic, stone, and clay products" in 2000. The intensity of kernel structure elements corresponding to these flows depends on each year, but sector members appeared in the ranking are stable through 4 years. Figure 2 shows stability of large elements of aggregated kernel structure matrix, those have potential to change GHG emissions irrespective of $\boldsymbol{F} \boldsymbol{L}$ and $\boldsymbol{B} \boldsymbol{L}$.

\subsection{Decomposition of Japanese GHG emissions}

\subsubsection{Effect of six determinants}

Figure 3 summarizes the effects of the six determinants defined in this study on Japanese GHG emissions ( $\Delta Q$ ) from 1990 to 2005. During this period, GHG emissions increased by a factor 1.0943, while the effect of direct emission factors, $\boldsymbol{d}$, increased by a factor 1.0313 , raising emissions. The Leontief inverse, $\boldsymbol{L}$, increased 1.0116 times, while final demand, $y$, likewise rose, by a factor 1.0489 . Decomposition of this effect of the Leontief inverse into four items reveals that the effect of forward linkage, $\boldsymbol{F L}$, decreased by a factor 0.9942 , while that of backward linkage, $\boldsymbol{B} \boldsymbol{L}$, increased by a factor 1.0565. The average of forward/backward linkage, $A V$, decreased by a factor 0.9743 and that of the kernel structure, $K S$, by a factor 0.9885 . Although the effect of the Leontief inverse is to increase emissions, the contribution of backward linkage is greater.

In the period 1995-2000, GHG emissions rose by a factor 1.0183 , the effect of $\boldsymbol{d}$ decreased by a factor 0.9169 , that of $\boldsymbol{L}$ increased by a factor 1.0539 and that of $y$ increased by a factor 1.0547. Decomposition of the Leontief inverse reveals that the effect of $\boldsymbol{F L}$ rose by a factor 1.0432, while that of $\boldsymbol{B L}$ likewise increased, by a factor 1.0022 .

Further, the effect of $A V$ decreased by a factor 0.9876 , while that of the kernel structure $K S$ increased by a factor 1.0198. Unlike the period 1990-1995, in terms of items and direction, items other than $A V$ exerted effects in the upward direction.

In the period 2000-2005 GHG emissions rose by a factor 1.0043, the effect of $d$ increased by a factor 1.0436 , that of $\boldsymbol{L}$ decreased by a factor 0.9354 and that of $\boldsymbol{y}$ increased by a factor 1.0288. Decomposition of the Leontief inverse reveals that the effect of $\boldsymbol{F} \boldsymbol{L}$ decreased by a factor 0.9094, while that of $\boldsymbol{B} \boldsymbol{L}$ increased by a factor 1.0274 . The effect of $A V$ decreased by a factor 0.9815 , while that of the kernel structure $K S$ increased by a factor 1.0200. Unlike the two previous periods, $y$ and the $A V$ predominated in the contribution of the Leontief inverse, which decreased for the first time.

\subsubsection{Comparison using the conventional approaches}

For $\boldsymbol{F L}$ and $\boldsymbol{B L}$ we compared our results with those obtained using the three conventional approaches, shown in Fig. 3b. In the following the percentage in parenthesis represents the error rate. The direction of $\boldsymbol{F L}$ effects on GHG emissions is the same in our 


\section{(a)}

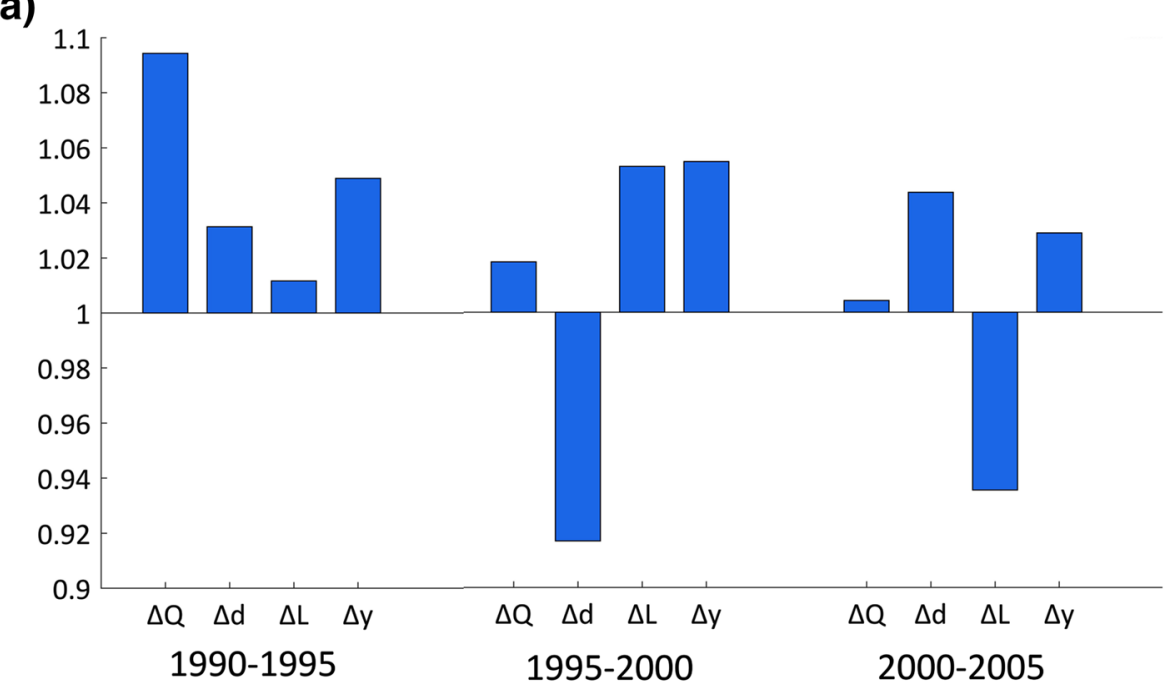

(b)

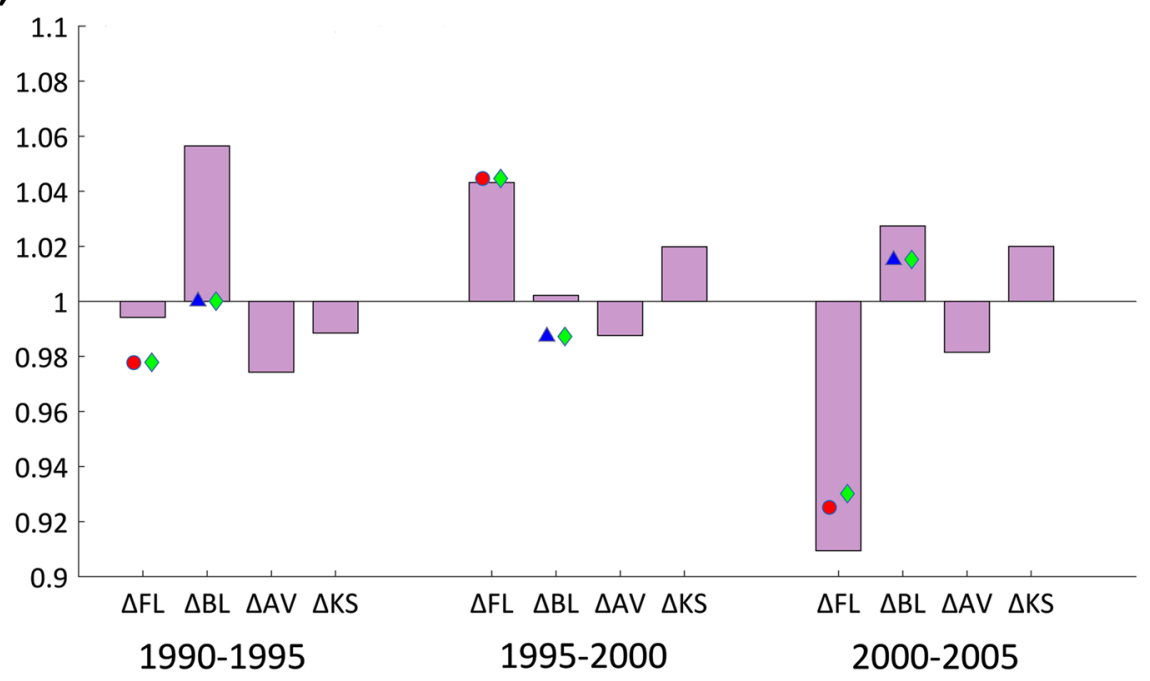

Fig. 3 Effects of the six determinants defined in this study and two linkages of conventional approaches on changing Japanese GHG emissions in three periods (1990-1995, 1995-2000 and 2000-2005). $\Delta$ Q means growth ratio of GHG. The other $\Delta$ mean the average effect of each determinant on GHG. a Shows $\Delta Q, \Delta \boldsymbol{d}, \Delta \boldsymbol{L} \Delta \boldsymbol{y}$. b Shows $\Delta F L, \Delta B L, \Delta A V, \Delta K S$. $\mathbf{b}$ Includes the results of comparison with conventional methods. Blue triangles show the effects by method 1: $\Delta \hat{\boldsymbol{B L}} \hat{\mathrm{I}}^{\mathrm{m}}$, red circles are by method $2: \Delta \breve{F L}^{\mathrm{m2}}$ and green diamonds are by method $3: \Delta \hat{\boldsymbol{B L}}^{\mathrm{m3}}, \Delta \breve{\boldsymbol{F} L}{ }^{\mathrm{m3}}$

method and the conventional methods throughout all periods. The $\boldsymbol{F} \boldsymbol{L}$ effects are 0.9777 $(-1.7 \%)$ by method 2 and $0.9778(-1.6 \%)$ by method 3 in the period 1990-1995. In the period 1995-2000 there are almost no differences: $1.0446(0.1 \%)$ by both conventional methods. In the last period, the figures are 0.9251 (1.7\%) by method 2 and 0.9301 (2.3\%) by method 3 . These two results from the conventional approach are close in value, but our value of 0.9094 differs. The direction of the $\boldsymbol{B} \boldsymbol{L}$ effects in our results and those from the other methods are partially different. Methods 1 and 3 both yield an effect of $1.0000(-5.3 \%)$ for the period 1990-1995 and $0.9872(-1.5 \%)$ for the period 19952000. Method 1 gives $1.0150(-1.2 \%)$ and method $31.0152(-1.2 \%)$ for the period 
2000-2005. The values yielded by the conventional approaches are similar for all periods. In the period 1995-2000, however, our result indicates a different direction of the $\boldsymbol{B} \boldsymbol{L}$ effect. This difference originates in the parameter dependency in SDA. If multiple parameters like $\boldsymbol{B} \boldsymbol{L}$ and $L^{m 1}$ are mutually dependent, there will be simultaneous update of the dependent parameters in SDA. In the case of $\boldsymbol{B} \boldsymbol{L}$ for 1995-2000, the dependency affects the sign of the effect.

\subsubsection{Sectoral contributions of forward and backward linkages}

This study also quantified the contributions of changes in the forward and backward linkages of each sector, $\Delta \boldsymbol{F} \boldsymbol{L}_{i}$ and $\Delta \boldsymbol{B} \boldsymbol{L}_{j}$, to Japan's national GHG emissions. We focused on those sectors for which both $\Delta \boldsymbol{F} \boldsymbol{L}_{i}$ and $\Delta \boldsymbol{B} \boldsymbol{L}_{j}$ are greater than unity, selecting the top 5 sectors with a large contribution from both $\Delta \boldsymbol{F} \boldsymbol{L}_{i}$ and $\Delta \boldsymbol{B} \boldsymbol{L}_{j}$.

In this case the high-scoring sectors are different from the case of $\boldsymbol{F} \boldsymbol{L}$ and $\boldsymbol{B} \boldsymbol{L}$ in Fig. 1. There are now a greater number of sectors involved, and no sector has a high score across all periods. Overall, the transport and material sectors make a large contribution to GHG emission in all periods.

Depicting $\Delta \boldsymbol{F} \boldsymbol{L}_{i}$ and $\Delta \boldsymbol{B} \boldsymbol{L}_{j}$ for each sector for 1990-1995, allows us to identify the sectors with both $\Delta \boldsymbol{F} \boldsymbol{L}_{i}>1$ and $\Delta \boldsymbol{B} \boldsymbol{L}_{j}>1$ that contributed most to rising GHG emissions. The top 5 sectors in this respect during this period were "Private power generation" $\left(\Delta \boldsymbol{F} \boldsymbol{L}_{i}=1.0188, \Delta \boldsymbol{B} \boldsymbol{L}_{j}=1.0012\right)$, "Cement" (1.0053, 1.0066), "Pig iron" (1.0011, 1.0025), "Video devices" $(1.0001,1.0019)$ and "In-house R\&D" (1.0015, 1.0001). There were 90 sectors with $\Delta \boldsymbol{F} \boldsymbol{L}_{i}>1$ and 141 sectors with $\Delta \boldsymbol{B} \boldsymbol{L}_{j}>1$, with an intersection of 34. All three figures are the highest in any of the periods considered.

$\Delta \boldsymbol{F} \boldsymbol{L}_{i}$ and $\Delta \boldsymbol{B} \boldsymbol{L}_{j}$ from 1995 to 2000 . The top 5 sectors driving increased GHG emissions are "Retail" (1.0026, 1.0017), "Liquid crystal elements" (1.0002, 1.0022), "Cement" (1.0018, 1.0003), "Internal combustion engines for motor vehicles" (1.0009, 1.0004), "Railway passenger transport" $(1.0008,1.0003)$. In this period there were 77 sectors with $\Delta \boldsymbol{F} \boldsymbol{L}_{i}>1,113$ sectors with $\Delta \boldsymbol{B} \boldsymbol{L}_{j}>1$, the minimum in any period, while their intersection comprised 15 sectors.

$\Delta \boldsymbol{F} \boldsymbol{L}_{i}$ and $\Delta \boldsymbol{B} \boldsymbol{L}_{j}$ from 2000 to 2005 . Compared with other two periods, the GHGemission relevant sectors now have a relatively small effect: "Road freight transport" (1.0016, 1.0001), "Printing and bookbinding" (1.0010, 1.0001), "Air transport" (1.0002, $1.0005)$, "Other organic chemical products" $(1.0002,1.0004)$ and "Open sea transport" $(1.0004,1.0001)$. In this period there were 69 sectors with $\Delta \boldsymbol{F} \boldsymbol{L}_{i}>1$, the smallest in any period, 135 sectors with $\Delta \boldsymbol{B} \boldsymbol{L}_{j}>1$, with an intersection of 11 sectors, which is again the least of any period.

Table 1 shows the 21 sectors with a robust effect of forward linkage on emissions growth or appearing above the baseline, $\Delta \boldsymbol{F} \boldsymbol{L}_{i}>1$. The sectors scoring highest in the three periods are "Plastic products" (1.0015) in 1990-1995, "Real estate rental services" (1.0009) in 1995-2000 and "Plastic products" (1.0013) again in 2000-2005. Table 2, on the other hand, lists the 34 sectors showing a consistent effect of backward linkage on emissions growth between 1990 and 2005. The sector with the greatest effect differs from period to period: "Cement" (1.0066) in 1990-1995, "Electronic computing equipment (except personal computers)" (1.0023) in 1995-2000, 
Table 1 Sectors whose forward linkage increased GHG emissions in Japan in all study periods (1990-1995, 1995-2000 and 2000-2005)

\begin{tabular}{|c|c|c|c|c|}
\hline \multirow[t]{2}{*}{ Sector number } & \multirow[t]{2}{*}{ Sector name } & \multicolumn{3}{|l|}{ Period } \\
\hline & & 1990-1995 & $1995-2000$ & 2000-2005 \\
\hline 22 & Silviculture & 1.0001 & 1.0002 & 1.0001 \\
\hline 87 & Timber & 1.0002 & 1.0002 & 1.0001 \\
\hline 99 & Corrugated cardboard boxes & 1.0001 & 1.0001 & 1.0001 \\
\hline 103 & Printing, plate making and book binding & 1.0008 & 1.0007 & 1.001 \\
\hline 107 & Compressed gas and liquefied gas & 1.0001 & 1.0003 & 1.0001 \\
\hline 138 & Plastic products & 1.0015 & 1.0005 & 1.0013 \\
\hline 155 & Carbon and graphite products & 1.0002 & 1.0001 & 1.0001 \\
\hline 168 & Cast iron pipes and tubes & 1.0001 & 1.0001 & 1.0001 \\
\hline 177 & Electric wires and cables & 1.0009 & 1.0004 & 1.0001 \\
\hline 190 & Other metal products & 1.0002 & 1.0003 & 1.0003 \\
\hline 211 & Other general machines and parts & 1.0002 & 1.0001 & 1.0001 \\
\hline 215 & Rotating electrical equipment & 1.0001 & 1.0001 & 1.0001 \\
\hline 218 & Wiring devices and supplies & 1.0003 & 1.0002 & 1.0001 \\
\hline 291 & Steam and hot water supply & 1.0002 & 1.0002 & 1.0003 \\
\hline 294 & Sewage disposal & 1.0009 & 1.0007 & 1.0004 \\
\hline 295 & Waste management services (public) & 1.0003 & 1.0003 & 1.0003 \\
\hline 303 & Real estate rental services & 1.0009 & 1.0009 & 1.0006 \\
\hline 310 & Ocean transport & 1.0005 & 1.0004 & 1.0004 \\
\hline 334 & Newspaper & 1.0005 & 1.0001 & 1.0003 \\
\hline 351 & Research and development (intra-enterprise) & 1.0015 & 1.0001 & 1.0005 \\
\hline 396 & Office supplies & 1.0001 & 1.0002 & 1.0002 \\
\hline
\end{tabular}

and "Engineering works relating to rivers, drainage channels and other waterways" (1.0018) in 2000-2005. No sectors appear in both tables.

\section{Discussion}

In this study, the Leontief inverse describing the supply chains of Japanese products was decomposed into four elements: $\boldsymbol{F L}, \boldsymbol{B L}, A V$ and $\boldsymbol{K S}$. Their respective contributions to increasing or decreasing GHG emissions in Japan during 1990-2005 were then identified quantitatively using SDA. As confirmed in Fig. 3, changes in forward linkage $(\boldsymbol{F L})$ contributed to reducing emissions during 1990-1995 and 2000-2005, whereas changes in backward linkage $(\boldsymbol{B} \boldsymbol{L})$ acted consistently to increase emissions. This trend differs from that observed for GHG emissions in Australia from 1990 to 2005 (Wood 2009), where changes in FL and BL led to emissions reduction on average. After 1998 in that period, however, BL did act consistently to increase emissions in Australia, this is common with the Japanese situation. This suggests that, to move the Leontief inverse further into a low-carbon supply chain structure, it is essential to improve the structure of $\boldsymbol{B L}$ itself in order to mitigate emissions. $\boldsymbol{B} \boldsymbol{L}$ is an index representing the degree to which a particular domestic industry induces production throughout the upstream supply chain per unit output by that industry. To achieve low-carbon $\boldsymbol{B L}$, it is therefore important to prioritize emissions reduction upstream in the supply chain by means of judicial procurement of raw materials and parts. At present, as a practical approach, GHG emissions from entire 
Table 2 Sectors whose backward linkage increased GHG emissions in Japan in all the study periods (1990-1995, 1995-2000 and 2000-2005)

\begin{tabular}{|c|c|c|c|c|}
\hline \multirow[t]{2}{*}{ Sector number } & \multirow[t]{2}{*}{ Sector name } & \multicolumn{3}{|l|}{ Period } \\
\hline & & 1990-1995 & 1995-2000 & 2000-2005 \\
\hline 16 & Fowls and broilers & 1.0001 & 1.0001 & 1.0005 \\
\hline 77 & Yarn and fabric dyeing and finishing & 1.0001 & 1.0001 & 1.0001 \\
\hline 94 & Pulp & 1.0012 & 1.0004 & 1.0008 \\
\hline 121 & Thermoplastics resins & 1.0003 & 1.0002 & 1.0003 \\
\hline 122 & High function resins & 1.0007 & 1.0004 & 1.0001 \\
\hline 131 & Photographic sensitive materials & 1.0005 & 1.0001 & 1.0003 \\
\hline 149 & Cement & 1.0066 & 1.0003 & 1.0001 \\
\hline 217 & Relay switches and switchboards & 1.0001 & 1.0004 & 1.0001 \\
\hline 227 & Household air conditioners & 1.0001 & 1.0002 & 1.0001 \\
\hline 231 & Radio and television sets & 1.0003 & 1.0003 & 1.0003 \\
\hline 237 & $\begin{array}{l}\text { Electronic computing equipment (except personal } \\
\text { computers) }\end{array}$ & 1.0019 & 1.0023 & 1.0012 \\
\hline 241 & Electron tubes & 1.0004 & 1.0008 & 1.0006 \\
\hline 243 & Magnetic tapes and disks & 1.0012 & 1.001 & 1.0012 \\
\hline 246 & Trucks, buses and other cars & 1.0008 & 1.0002 & 1.0006 \\
\hline 248 & Motor vehicle bodies & 1.0005 & 1.0004 & 1.0008 \\
\hline 259 & Bicycles & 1.0003 & 1.0004 & 1.0004 \\
\hline 267 & Toys and games & 1.0001 & 1.0003 & 1.0002 \\
\hline 276 & Residential construction (wooden) & 1.0014 & 1.0005 & 1.0009 \\
\hline 277 & Residential construction (non-wooden) & 1.0023 & 1.0011 & 1.0009 \\
\hline 279 & Non-residential construction (non-wooden) & 1.0055 & 1.0008 & 1.0014 \\
\hline 281 & Public construction of roads & 1.0013 & 1.0011 & 1.0008 \\
\hline 282 & Public construction of rivers, drainages and others & 1.0019 & 1.0006 & 1.0018 \\
\hline 283 & Agricultural public construction & 1.0003 & 1.0003 & 1.0004 \\
\hline 287 & Other civil engineering and construction & 1.0003 & 1.0005 & 1.0006 \\
\hline 338 & Public administration (local) & 1.0018 & 1.0008 & 1.001 \\
\hline 340 & School education (private) & 1.0001 & 1.0004 & 1.0009 \\
\hline 369 & Repair of motor vehicles & 1.0004 & 1.0001 & 1.0002 \\
\hline 379 & $\begin{array}{l}\text { Stadiums and companies of bicycle, horses, motor- } \\
\text { car and motorboat races }\end{array}$ & 1.0002 & 1.0001 & 1.0001 \\
\hline 382 & General eating and drinking places & 1.0013 & 1.002 & 1.0011 \\
\hline 383 & Coffee shops & 1.0003 & 1.0001 & 1.0001 \\
\hline 384 & Eating and drinking places pleasure & 1.0018 & 1.0006 & 1.0004 \\
\hline 385 & Hotels & 1.0007 & 1.0007 & 1.0007 \\
\hline 392 & Ceremonial occasions & 1.001 & 1.0001 & 1.0001 \\
\hline 394 & Supplementary tutorial schools & 1.0002 & 1.0002 & 1.0001 \\
\hline
\end{tabular}

value chains of business enterprises are being tackled and managed under international guidelines such as the "GHG protocol" (World Resources Institute and World Business Council 2017) developed by the World Resources Institute and World Business Council on Sustainable development, which distinguishes three types of emissions. Scope 1 emissions are on-site emissions at the production site, scope 2 emissions derive from electric power and heat sourced elsewhere, while scope 3 emissions cover a wide range of other emission sources in the value chain. In the scheme established by this protocol, 15 categories are defined in scope 3 indicating which emissions should be counted. 
Large elements in $K S$ have high possibility to have large element also in $L$ and $d L$, irrespective of the values of $\boldsymbol{F} \boldsymbol{L}$ and $\boldsymbol{B L}$. It means that the sectors corresponding to the large elements have potential of wide effect on upstream of supply chain, and they may relate to GHG emission increase. Large $\boldsymbol{F} \boldsymbol{L}$ and $\boldsymbol{B L}$ elements in Fig. 1 do not always contribute to GHG emission increase. It means the importance to check the structural information, not only the monetary information like $\boldsymbol{F} \boldsymbol{L}$ and $\boldsymbol{B} \boldsymbol{L}$. $\boldsymbol{K S}$ contributes to GHG emissions increase in the periods of 1995-2000 and 2000-2005. The growing sectors in $K S$ have possibility of large ripple effect on GHG emission increase in the future. The sectors in the top list is different from the striking sectors in $\boldsymbol{F} \boldsymbol{L}$ and $\boldsymbol{B} \boldsymbol{L}$ with large values. Using 21 sector classification, $K S$ is stable through all periods. This stability means that $K S$ is useful to see through the future priority industries as policy targets, though it is difficult to forecast the future supply and demand. In order to find out the sectors with high potentials or potential trends for GHG emission increase, invariant $K S$ elements are important. Regardless of demand in economy, these potential sectors from $\boldsymbol{K S}$ need environmental measures.

In the environmental input-output model of this study, electric power and heat supply in intermediate sectors are defined as the intermediate sectors; capital formation is included in the final demand sectors, while the consumption of goods and services associated with lease assets cannot be appropriately captured. Considering these properties, $\boldsymbol{B} \boldsymbol{L}$ almost corresponds to scope 2, while the following categories fall under scope 3: supply chains of purchased products and services (category 1 ), fuel and energy related activities not included in scope 1 and 2 (category 2), transportation and distribution (category 4) and business transportation (category 6).

To achieve low-carbon $\boldsymbol{B L}$, in addition to scope 2 emissions reduction, extensive efforts should be undertaken to mitigate emissions associated with the categories of scope 3 described above, especially in industries where scope 3 emissions are greater than those under scopes 1 and 2. Switching to suppliers with lower emissions, collaboration with suppliers on technological development geared to emissions reduction and improved logistics will all effectively contribute to reducing such emissions. Policy support for such measures is of course indispensable. Specific incentives might include provision of official emissions factors so that business enterprises can estimate their emissions, creating opportunities for enterprises to share information and rewarding firms that successfully tackle emissions reduction in entire supply chains. Furthermore, government agencies and municipalities calling on suppliers to report scope 3 emissions in public procurement will be an effective means to remind industries of the need for low-carbon supply chains.

The findings of this paper should help business enterprises in Japan identify which direction of the supply chain (backward versus forward) should be preferentially managed for optimum GHG reduction. Such prioritization needs to be undertaken above all by Japanese industries in supply chains where emissions continue to rise. Table 2 identifies those sectors where changes in $\boldsymbol{B} \boldsymbol{L}$ consistently contributed to increasing emissions $(\Delta \boldsymbol{B} \boldsymbol{L}>1)$ during $1990-2005$. Of these, "Engineering works relating to rivers, drainage channels and other waterways", "Non-residential construction (non-wooden)", "Electronic computing equipment (except personal computers)", "Magnetic tapes and disks" and "General eating and drinking places (except coffee shops)" show a marked 
increase in emissions during 2000-2005. For these goods and services, low carbonization of scope 2 supply chains and the aforementioned scope 3 categories should be promoted extensively. For example, industries producing final products such as magnetic media and computers should switch to suppliers of materials and parts generating lower emissions. Construction industries also need to induce their suppliers of construction materials to reduce emissions, while at the same time policy support to promote such activities should also be given. Such support might include an obligation to report supply chain emissions in bids for public construction projects and creation of tax incentives for construction projects conforming to certain standards in terms of supply chain emissions.

Changes in $\boldsymbol{F L}$ contributed to a decrease in the emissions of the nation as a whole. Perusal of the $\boldsymbol{F} \boldsymbol{L}$ of individual sectors shows, however, that the emissions of certain sectors listed in Table 1 continued to increase $(\Delta \boldsymbol{F L}>1)$ ) from 1990 to 2005. In concreto, "Plastic products", "Printing, plate making and book binding", "Real estate rental services", "Research and development (intra-enterprise)" and "Sewage disposal" are the top five sectors showing large changes from 2000 to 2005. Changes in $\boldsymbol{F L}$ reflect changes in the structure of a sector feeding into other sectors. Industries using petrochemical products such as plastics and printing ink should enhance their low-carbon management viaà-vis supply destinations, i.e., downstream supply chains. For example, long-term use of products, promotion of collection and reuse of used products could be effective measures. Also, cost reduction in rent and waste disposal in each industry would effectively lead to GHG reduction.

This study has demonstrated that the sectors presented above are not necessarily identical to the key sectors exhibiting high $\boldsymbol{F L}$ and $\boldsymbol{B} \boldsymbol{L}$ in Fig. 1. This result implies that even if attention is focused entirely on those sectors with the greatest influence on the supply chain in terms of monetary value, this is unlikely to result in effective emissions reduction. After all, to properly manage supply chains, the GHG-inducing structure should be thoroughly tackled as well as monetary aspects. Opportunities to decarbonize the supply chain should be sought from both perspectives. Today, with ESG (Environment, Social, Governance) investment being encouraged, in line with the United Nations' Principles for Responsible Investment (United Nations 2017), companies are under growing obligation to disclose supply chain emissions. When it comes to emissions disclosure, institutional investors that are major players in ESG investment should focus specifically on companies operating in the sectors cited above, further motivating them to improve management of their supply chains. Although domestic supply chains are targeted in this study, it should be noted that imported goods should also be included in such management, for otherwise the overseas emissions associated with imports may lead to increased consumption-based emissions in Japan.

Finally, we refer to the methodological prospects of this study. We applied information geometry to an IO model for the first time and discovered the kernel structure matrix of the RAS invariants. Finding the kernel structure matrix also theoretically enhances compilation of national, regional and international IO tables by the RAS method, for example. Other possible applications of kernel structure are factorization and sectoral clustering for detail analysis of supply chain (Kagawa et al. 2013a, b), since structural information is interpreted as a sectoral adjacent matrix of supply chain. Sectoral 
adjacent matrix has availability for various network analyses. Until now, informationgeometric ideas have only rarely been applied to IO analyses, but geometry would be a truly useful tool for understanding existing methodologies and developing new ones.

\section{Additional file}

Additional file 1. Numerical examples with Leontief inverse and List of sector names.

\section{Author details}

${ }^{1}$ Center for Material Cycles and Waste Management Research, National Institute for Environmental Studies, 16-2 Onogawa, Tsukuba, Ibaraki 305-8506, Japan. ${ }^{2}$ Integrated Sustainability Analysis (ISA), School of Physics, Faculty of Science, The University of Sydney, Camperdown, NSW 2006, Australia. ${ }^{3}$ Graduate School of Frontier Sciences, The University of Tokyo, 5-1-5 Kashiwa-no-ha, Kashiwa, Chiba 277-8561, Japan.

\section{Authors' contributions}

RM was responsible for performing model calculations and positioning of the structural information in this application research. KN designed data collection and SDA application for analyzing GHG emissions. KT interpreted the structural information in the decomposition. All authors read and approved the final manuscript.

\section{Acknowledgements}

The authors are grateful to editors and anonymous referees for their useful comments and suggestions for revising the paper.

\section{Competing interests}

The authors declare that they have no competing interests.

\section{Availability of data and materials}

Not applicable.

Ethics approval and consent to participate

Not applicable.

Funding

This work was supported in part by JSPS KAKENHI (Grant Numbers 16K16231, 16H01797); The Environment Research \& Technology Development Fund of the Japanese Ministry of Environment [Grant Number 1-1601].

Publisher's Note

Springer Nature remains neutral with regard to jurisdictional claims in published maps and institutional affiliations.

Received: 27 December 2017 Accepted: 16 April 2018

Published online: 01 May 2018

\section{References}

Afrasiabi A, Casler S (1991) Product-mix and technological change within the leontief inverse. J Reg Sci 31(2):147-160

Alatriste-Contreras M (2015) The relationship between the key sectors in the European union economy and the intraEuropean union trade. J Econ Struct 4(14):1-24

Amari S, Nagaoka H (2000) Methods of information geometry. Oxford University Press, Oxford

Beyers W (1976) Empirical identification of key sectors—some further evidence. Environ Plan A 8(2):231-236

Bullard C, Sebald A (1977) Effects of parametric uncertainty and technological change in input-output models. Rev Econ Stat 59:75-81

Censor Y, Zenios S (1997) Parallel optimization. Oxford University Press, Oxford

Chang N, Lahr M (2017) Changes in China's production-source $\mathrm{CO}_{2}$ emissions: insights from structural decomposition analysis and linkage analysis. Econ Syst Res 28(2):224-242

de Mesnard L (2004) Biproportional methods of structural change analysis: a typological survey. Econ Syst Res 16(2):205-230

Dietzenbacher E (1997) In vindication of the Ghosh model: a reinterpretation as a price model. J Reg Sci 37(4):629-651 Dietzenbacher E, Hoekstra R (2002) The RAS structural decomposition approach. In: Hewings G, Sonis M, Boyce D (eds) Trade, networks and hierarchies: modelling regional and interregional economies. Springer, Berlin

Dietzenbacher E, Los B (1998) Structural decomposition techniques: sense and sensitivity. Econ Syst Res 10:307-323

Dietzenbacher E, Hoen A, Los B (2000) Labor productivity in western Europe 1975-1985: an intercountry, interindustry analysis. J Reg Sci 40:425-452

Haque A, Jahan S (2016) Regional impact of cyclone sidr in Bangladesh: a multi-sector analysis. J Econ Struct $7(100): 312-327$ 
Hewings G, Romanos M (1981) Simulating less-developed regional economies under conditions of limited information. Wiley, New York

Hewings G, Fonseca M, Guilhoto J, Sonis M (1989) Key sectors and structural change in the Brazilian economy: a comparison of alternative approaches and their policy implications. J Policy Model 11(1):67-90

Hirschman A (1958) The strategy of economic development. Yale University Press, New Haven

Humavindu M, Stage J (2013) Key sectors of the Namibian economy. J Econ Struct 2(1):1-15

Jones L (1976) The measurement of hirschmanian linkages. Struct Change Econ Dyn 90(2):323-333

Kagawa S, Okamoto S, Suh S, Kondo Y, Nansai K (2013a) Finding environmentally important industry clusters: multiway cut approach using nonnegative matrix factorization. Soc Netw 35(3):423-438

Kagawa S, Suh S, Kondo Y, Nansai K (2013b) Identifying environmentally important supply chain clusters in the automobile industry. Econ Syst Res 25(3):265-286

Lahr M, de Mesnard L (2004) Biproportional techniques in input-output analysis: table updating and structural analysis. Econ Syst Res 16:115-134

Lenzen M (2003) Environmentally important paths, linkages and key sectors in the australian economy. Struct Change Econ Dyn 14:1-34

Lianling Y, Cuihong Y (2017) Changes in domestic value added in China's exports: a structural decomposition analysis approach. J Econ Struct 6(18):1-12

Miller R, Blair P (2009) Input-output analysis: foundations and extensions. Cambridge University Press, Cambridge

Minx J, Baiocchi G, Peters G, Weber C, Guan D, Hubacek K (2011) A "Carbonizing Dragon": China's fast growing $\mathrm{CO}_{2}$ emissions revisited. Environ Sci Technol 45:9144-9153

Nagashima F, Kagawa S, Suh S, Nansai K, Moran D (2017) Identifying critical supply chain paths and key sectors for mitigating primary carbonaceous PM\$_2.5\$ mortality in Asia. Econ Syst Res 29:105-123

Keisuke N, Moriguchi Y, Tohno S (2003) Compilation and application of Japanese inventories for energy consumption and air pollutant emissions using input-output tables. Environ Sci Technol 37(9):2005-2015

Nansai K, Kagawa S, Suh S, Inaba R, Moriguchi Y (2007) Simple indicator to identify the environmental soundness of growth of consumption and technology: "Eco-velocity of Consumption". Environ Sci Technol 41:1465-1472

Okuyama Y, Sonis M, Hewings G (2006) Typology of structural change in a regional economy: a temporal inverse analysis. Econ Syst Res 18(2):133-153

Rasmussen P (1956) Studies in inter-sectoral relations. Einar Harks, Copenhagen

Sherman J, Morrison W (1949) Adjustment of an inverse matrix corresponding to changes in the elements of a given column or a given row of the original matrix (abstract). Ann Math Stat 20:621

Sherman J, Morrison W (1950) Adjustment of an inverse matrix corresponding to a change in one element of a given matrix. Ann Math Stat 21:124-127

Sonis M, Hewings G (1998) Temporal leontief inverse. Macroecon Dyn 2:89-114

Sonis M, Hewings G, Guo J (2000) A new image of classical key sector analysis: minimum information decomposition of the leontief inverse. Econ Syst Res 12(3):401-423

United Nations (2017) ESG (Environment, Social, Governance) investment. https://www.unpri.org/. Accessed 15 Sept 2017

van der Linden J, Dietzenbacher E (2000) The determinants of structural change in the European Union: a new application of RAS. Environ Plan A 32:2205-2229

Vazquez E, Hewings G, Carvajal CR (2015) Adjustment of input-output tables from two initial matrices. Econ Syst Res 27(3):345-361

Wood R (2009) Structural decomposition analysis of Australiaś greenhouse gas emissions. Energy Policy 37:4943-4948

Woodbury M (1950) Inverting modified matrices. Memorandum report no. 42, Statistical Research Group, Princeton University, Princeton

World Resources Institute and World Business Council (2017) GHG protocol. http://www.ghgprotocol.org/. Accessed 15 Sept 2017

Yamakawa A, Peters G (2011) Structural decomposition analysis of greenhouse gas emissions in norway 1990-2002. Econ Syst Res 23(3):303-318

Zhang H, Lahr M, Bi J (2017) Challenges of green consumption in China: a household energy use perspective. Econ Syst Res 28(2):183-201

\section{Submit your manuscript to a SpringerOpen ${ }^{\circ}$ journal and benefit from:}

- Convenient online submission

- Rigorous peer review

- Open access: articles freely available online

- High visibility within the field

Retaining the copyright to your article

Submit your next manuscript at $\gg$ springeropen.com 